Randomized Trial

\title{
High-Voltage, Long-Duration Pulsed Radiofrequency on Gasserian Ganglion Improves Acute/Subacute Zoster-Related Trigeminal Neuralgia: A Randomized, Double-Blinded, Controlled Trial
}

\author{
Chengfu Wan, MD, Dao-song Dong, MD, and Tao Song, MD
}

From: The First Affiliated Hospital of China Medical University, China

Address Correspondence: Tao Song, MD The First Affiliated Hospital of China Medical University, China

No.155, Nanjing North Street, Shenyang, Liaoning, China E-mail: songtaocmu@163.com

Disclaimer: There was no external funding in the preparation of this manuscript. Conflict of interest: Each author certifies that he or she, or a member of his or her immediate family, has no commercial association (i.e., consultancies, stock ownership, equity interest, patent/licensing arrangements, etc.) that might pose a conflict of interest in connection with the submitted manuscript.

Manuscript received: 12-09-2018 Revised manuscript received: 02-12-2019 Accepted for publication: 02-27-2019

Free full manuscript: www.painphysicianjournal.com
Background: Trigeminal postherpetic neuralgia is a severe neuropathic pain and often refractory to existing treatment, it develops secondary to herpes zoster-infected Gasserian ganglion. Therefore, it is important to prevent the transition of acute/subacute zoster-related pain to trigeminal postherpetic neuralgia. Despite numerous studies, the optimal intervention that reduces trigeminal postherpetic neuralgia incidence is still unknown.

Objectives: This study aimed to evaluate the efficacy and safety of high-voltage, long-duration pulsed radiofrequency (PRF) on the Gasserian ganglion in patients with acute/subacute zosterrelated trigeminal neuralgia.

Study Design: Prospective, randomized, double-blinded study.

Setting: Department of Pain Medicine, the First Affiliated Hospital of China Medical University.

Methods: Ninety-six patients with acute/subacute zoster-related trigeminal neuralgia were equally randomly assigned into 2 groups. The electrode needle punctured the Gasserian ganglion guided by computed tomography in every patient. High-voltage, long-duration PRF at $42^{\circ} \mathrm{C}$ for 900 seconds was applied in the PRF group $(n=48)$. It was also applied in the sham group ( $n=$ 48) without radiofrequency energy output. The therapeutic effects were evaluated using a visual analog scale (VAS) and the 36-Item Short Form Health Survey (SF-36) at different time points. The average dosage of pregabalin $(\mathrm{mg} / \mathrm{d})$ administrated within the first month after treatment was also recorded.

Results: The postprocedure VAS scores in the PRF group were significantly lower than those in the sham group at different time points after treatment $(P<0.01)$. The SF-36 scores, which included physical functioning, physical role, bodily pain, general health perceptions, vitality, social function, emotional role, and the mental health index, were significantly improved at the sixth month after treatment in the PRF group compared with the sham group $(P<0.01)$. The average dosage of pregabalin administered $(\mathrm{mg} / \mathrm{d})$ within the first month after treatment was also significantly reduced in the PRF group compared with the sham group $(P<0.01)$. There were no bleeding, infection, or other severe side effects in both groups.

Limitations: Single center study, relatively small number of patients.

Conclusions: High-voltage, long-duration PRF on the Gasserian ganglion is an effective and safe therapeutic alternative for patients with acute/subacute zoster-related trigeminal neuralgia.

Key words: Pulsed radiofrequency, zoster-related trigeminal neuralgia, visual analog scale, 36Item Short Form Health Survey

Pain Physician 2019: 22:361-368 
H

erpes zoster ( $\mathrm{HZ})$ is caused by the reactivation of varicella zoster virus after being latent in the sensory ganglia $(1,2)$. Postherpetic neuralgia (PHN) is the most common and severe syndrome resulting from $\mathrm{HZ}$. Painful trigeminal neuropathy attributed to $\mathrm{HZ}$ was described as unilateral facial pain of $<3$ months duration in the distribution(s) of one or more branches of the trigeminal nerve, caused by and associated with other symptoms and/or clinical signs of acute $\mathrm{HZ}$ (3). Patients with trigeminal PHN often suffered more severe facial pain and had a poor quality of life $(4,5)$. The mechanism of trigeminal PHN was multiple $(6,7)$, however, there was no effective treatments to cure trigeminal PHN (8).

There are several risk factors associated with a higher risk to develop PHN $(9,10)$ such as older age, severe acute pain, and severe rash. However, effective management for PHN remains largely obscure. Therefore, it is better to avoid the transition of acute/subacute $\mathrm{HZ}$ pain to $\mathrm{PHN}$, and this prevention strategy is in line with international perception concerning chronic pain management $(11,12)$.

Pulsed radiofrequency (PRF) is a novel therapeutic strategy that has recently been used (13) by pain practitioners as a non- or minimally neurodestructive technique in which short bursts of high-frequency current are applied to nervous tissue. PRF is delivered in a pulse of $20 \mathrm{~ms}$ followed by a silent period of $480 \mathrm{~ms}$ to avoid radiofrequency heat lesions (14). This novel therapeutic strategy has recently been used to treat PHN (15), and we have confirmed that high-voltage, long-duration PRF on dorsal root ganglions represents an effective and safe method for patients with PHN (16). Thus, the aim of this study was to verify high-voltage, longduration PRF on the Gasserian ganglion could improve acute/subacute zoster-related trigeminal neuralgia.

\section{Methods}

\section{Study Patients}

In accordance with the ethical principles of the Declaration of Helsinki, the current study was designed as a prospective, randomized controlled clinical trial conducted from June 1, 2016 to September 1, 2018. The study protocol was approved by the human ethics committee of the First Affiliated Hospital of China Medical University (No: 2016-175-15). All patients read the informed consent form and agreed to the therapeutic protocol. This trial was registered with chictr.org.cn (number ChiCTRIPR-16015375. Consent forms were signed by patients.

\section{Inclusion Criteria}

Eligible patients were aged $>60$ years and had a $\mathrm{HZ}$ history $<90$ days. Additional inclusion criteria comprised individuals with $\mathrm{HZ}$ who had been refractory to formal treatment, such as antiepileptic medicine, antidepressants, opioids, or physical treatments, according to the International Association for the Study of Pain guidelines (17), and a visual analog scale (VAS) score $\geq 5$ on a scale of 0 to 10 .

\section{Exclusion Criteria}

The exclusion criteria included intolerance to the study procedures, coagulation disorders or applied anticoagulant, uncooperative behavior (i.e., the patient did not provide an immediate response), or the intellectual inability to complete the self-evaluation questionnaires (VAS and 36-Item Short Form Health Survey [SF-36]).

\section{Randomization and Sequence Generation}

A total of 143 patients were initially enrolled. However, 47 patients had to be excluded because of refusal to participate or they did not meet inclusion criteria (29 patients did not meet inclusion criteria, 10 patients declined to participate, and 8 patients for other reasons). Therefore, 96 patients were finally enrolled and randomly assigned by means of a computer-generated random allocation sequence into one of 2 groups: a PRF group in which high-voltage, long-duration PRF on the Gasserian ganglion was applied $(n=48)$, or a sham group in which the method was followed as in the PRF group except that radiofrequency energy was not applied $(n=48)$ (Fig. 1).

\section{Description of PRF}

All patients were treated in the supine position and received $3 \mathrm{~L}$ per minute of oxygen. Oxygen saturation, heart rate, and respiratory rate were monitored continuously after they reached the operation room.

Computed tomography (CT) was used to determine the route of percutaneous insertion. The insertion point was marked on the skin of the cheek. After sterilization and local anesthesia with $0.5 \%$ lidocaine, a $20-\mathrm{G}$ insulated needle $(14.5 \mathrm{~cm}$, with a $10-\mathrm{mm}$ active tip, Baylis Medical Company, Montreal, Canada) was inserted and slowly advanced toward the foramen ovale along the designated path. When the depth of the needle reached the predefined depth, a new CT scan was performed to confirm the proper location of the needle tip. Thereafter, electrical stimulation was 


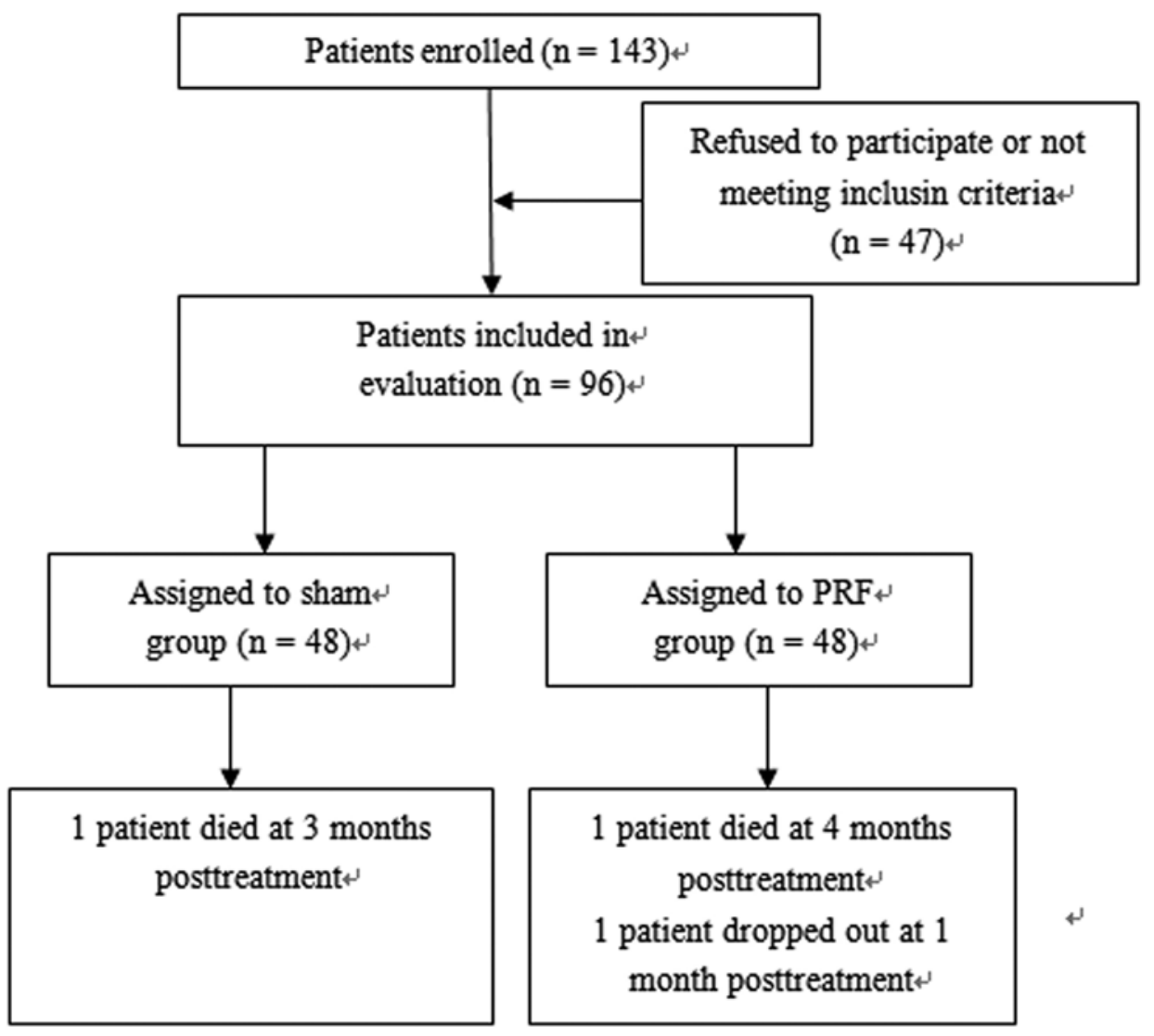

Fig. 1. Flowchart showing assignment of 96 patients randomly assigned to the intervention and control groups.

performed (sensory [50 Hz] and motor [2 Hz]) and the needle position adjusted until the stimulation elicited paresthesia in the affected area (Fig. 2).

After the Gasserian ganglion were attained, PRF treatment was performed using the Pain Management Generator (PM-230, Baylis Medical Company). The PRF mode with the basic settings of $42^{\circ} \mathrm{C}, 2 \mathrm{~Hz}, 20 \mathrm{~ms}$, and 900 seconds was used. The initial electric voltage was $40 \mathrm{~V}$, which was then gradually increased until the patients could not tolerate the abnormal sensations (e.g., burning pain). All patients tolerated their individual maximal voltage (60-90 V) until the 900 second PRF was terminated (Fig. 3).

\section{Blinding}

The PRF procedures were performed by the same investigator (T.S.) and all follow-ups were performed by another investigator (W.C. and D.D.). The doctors participating in the PRF treatment or follow-up activities were unaware of the groupings or the mode of the PRF used for each patient. The instrument was operated by a nurse (Y.S.) of our pain management center. The high-voltage, long-duration PRF was applied to the PRF group, with the same procedure applied to the sham group without any energy output. The nurse did not participate in any other therapeutic and follow-up activities or trial discussions.

\section{Drug Administration}

The patients were administered pregabalin after treatment for pain control according to the severity of the pain. The other medication treatments were avoided. The dosage was increased or reduced according to the alteration of the pain severity. 


\section{Outcome Measures}

\section{VAS}

The VAS scores were evaluated before treatment and in the morning on days 3,7 , and 14 , and month 1 , 3 , and 6 after treatment.

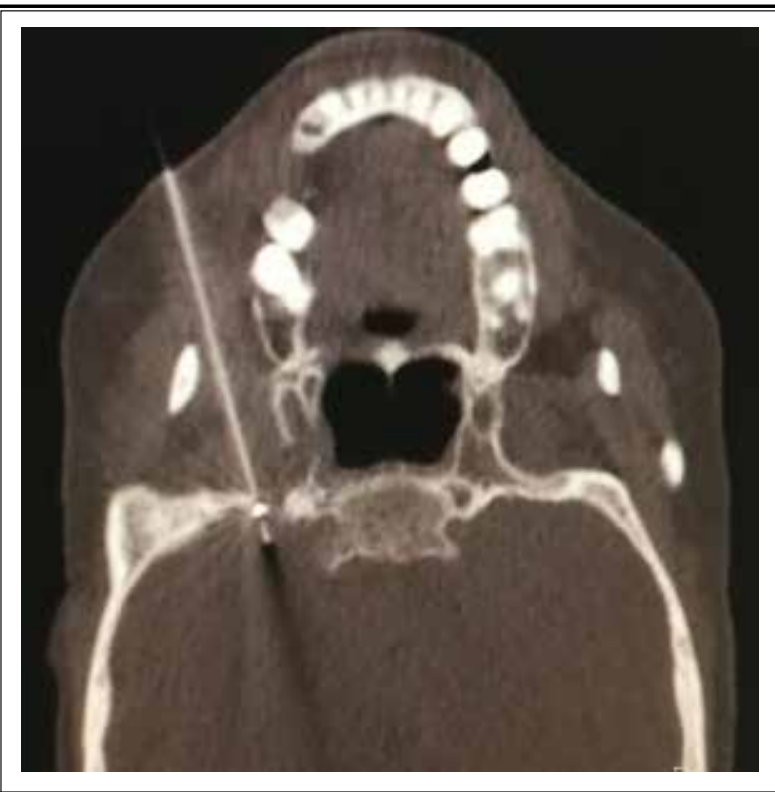

Fig. 2. Representative CT image of the electrode needle puncturing the Gasserian ganglion.

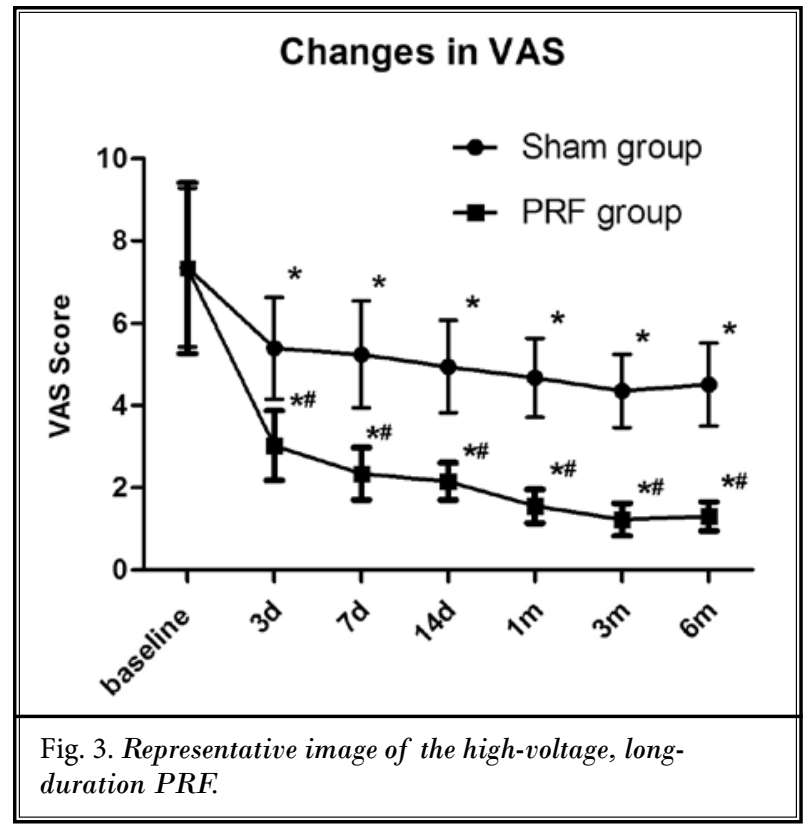

\section{SF-36 Score Evaluation}

The SF-36 health survey $(12,18)$ was used to assess the health of the patients with PHN. Patients needed only 6 to 9 minutes to complete the test. The SF- 36 assesses nearly all conceptual domains of the substantially longer generic patient-based assessments, which have been used in other studies (19). The scores, including physical functioning, physical role, bodily pain, general health perceptions, vitality, social function, emotional role, and mental health index, were also evaluated before treatment and on day 7 , and month 1, 3, and 6 after treatment.

\section{Average Dosage of Rescue Medication}

Pregabalin $50-100 \mathrm{mg}$ once every 12 hours orally was used as rescue medication for pain control at VAS $\geq 3$ and when the frequency of acute pain flares was $>3$ times per day. The average dosages of pregabalin (mg/d) were collected on days 1, 3, 7, 14, and 28 after the treatment in each group.

\section{Side Effects}

Any side effects, including bleeding at the puncture site, infection, intracranial hemorrhage, and other adverse reactions were recorded at days 1,3 , and 7 after treatment.

\section{Statistical Analysis}

\section{Sample Size}

According to our pilot study, the effective rate of the peripheral nerve adjustment in the test group was $70 \%$, and the effective rate in the positive control group was $20 \%$, so the difference between the effective rates in the 2 groups was $50 \%$. Based on this information, we then calculated that the estimated sample number was at least 23 in each group, which provided $80 \%$ power and a level of statistical significance of 0.05 $(\alpha=0.05)$. Quantitative data were presented as mean and standard deviation (SD).

\section{Data Analysis}

Numeric variables are expressed as mean \pm SD values and the number of observations. Categorical variables are described using the number of frequencies and percentages. To assess whether group differences were compatible with pure chance, exploratory tests were performed. Therefore, all reported $P$ values are descriptive. Associations of age with categorical variables were assessed by the 2-sample Wilcoxon test. 
PRF on Gasserian Ganglion Improves Acute/Subacute Zoster-Related Trigeminal Neuralgia

Association of categorical variables was tested using the Fisher exact test. Statistical analysis was performed using the Statistical Package for Social Sciences Version 19.0 (IBM Corporation, Armonk, NY). A $P$ value $<0.05$ was considered to be statistically significant.

\section{REsULts}

\section{Patient Demographics}

The demographic characteristics of the patients, such as age, gender, weight, disease duration, pain scores, and trigeminal neuropathy distribution before treatment were similar between the 2 groups (Table 1). One patient in the sham group and one patient in the PRF group survived $<6$ months, and 1 patient dropped out at 3 months in the PRF group, so we will eliminate their experimental data.

\section{VAS}

There was no significant difference in mean VAS score before treatment in the 2 groups. After treatment, there was significant decline in both groups at different time points ( ${ }^{*} P<0.01$; Fig. 4), but VAS scores significantly declined at each time point after treatment in the PRF group compared with the sham group $(\# P<$ 0.01 ; Fig. 4).

\section{SF-36}

There was no significant difference in baseline of SF-36 scores before treatment in the 2 groups, but the index scores in general health, social function, emotional role, mental health index, bodily pain, physical function, and physical role exhibited significant improvements at different time point after treatment in both groups ( ${ }^{*} P<0.01$; Fig. 5). Thus, these index scores could significantly improve at each time point after treatment in the PRF group compared with the sham group (\#P< 0.01; Fig. 5).

\section{Rescue Drug Dosage}

The rescue drug (pregabalin) dosage administration per day was lower in the PRF group than those in the sham group at each time point after treatment $(* P$ $<0.01$; Fig. 6).

\section{Side Effects}

The main adverse reactions during PRF treatment included pain, tachycardia, and high blood pressure (especially when the field strength was enhanced). Drugs were administered to treat these symptoms, and the
Table 1. Baseline characteristics of the patients (mean $\pm S D$ ).

\begin{tabular}{|c|c|c|}
\hline Patients & $\begin{array}{c}\text { Sham Group } \\
n=48 \\
\text { (completed 47) }\end{array}$ & $\begin{array}{c}\text { PRF Group } \\
\text { n=48 } \\
\text { (completed 46) }\end{array}$ \\
\hline Age (years) & $\begin{array}{c}64.87 \pm 15.21 \\
(65.96 \pm 13.66)\end{array}$ & $\begin{array}{c}66.01 \pm 12.28 \\
(65.54 \pm 13.28)\end{array}$ \\
\hline Female/male, $\mathrm{n}$ & $\begin{array}{l}28 / 20 \\
(27 / 20)\end{array}$ & $\begin{array}{c}25 / 23 \\
(25 / 21)\end{array}$ \\
\hline Weight (kg) & $\begin{array}{c}67.46 \pm 10.23 \\
(68.19 \pm 11.67)\end{array}$ & $\begin{array}{c}65.98 \pm 12.98 \\
(65.64 \pm 11.47)\end{array}$ \\
\hline Disease duration (days) & $\begin{array}{c}62.88 \pm 18.21 \\
(63.14 \pm 18.53)\end{array}$ & $\begin{array}{c}59.95 \pm 21.72 \\
(59.28 \pm 16.64)\end{array}$ \\
\hline Average pain scores & $\begin{array}{c}7.23 \pm 2.50 \\
(7.31 \pm 2.39)\end{array}$ & $\begin{array}{c}7.35 \pm 2.27 \\
(7.32 \pm 2.33)\end{array}$ \\
\hline $\begin{array}{l}\text { Trigeminal distribution } \\
\text { ( I/II/III branch), } \mathrm{n}\end{array}$ & $\begin{array}{l}7 / 15 / 26 \\
(7 / 15 / 25)\end{array}$ & $\begin{array}{c}6 / 17 / 25 \\
(5 / 17 / 24)\end{array}$ \\
\hline
\end{tabular}

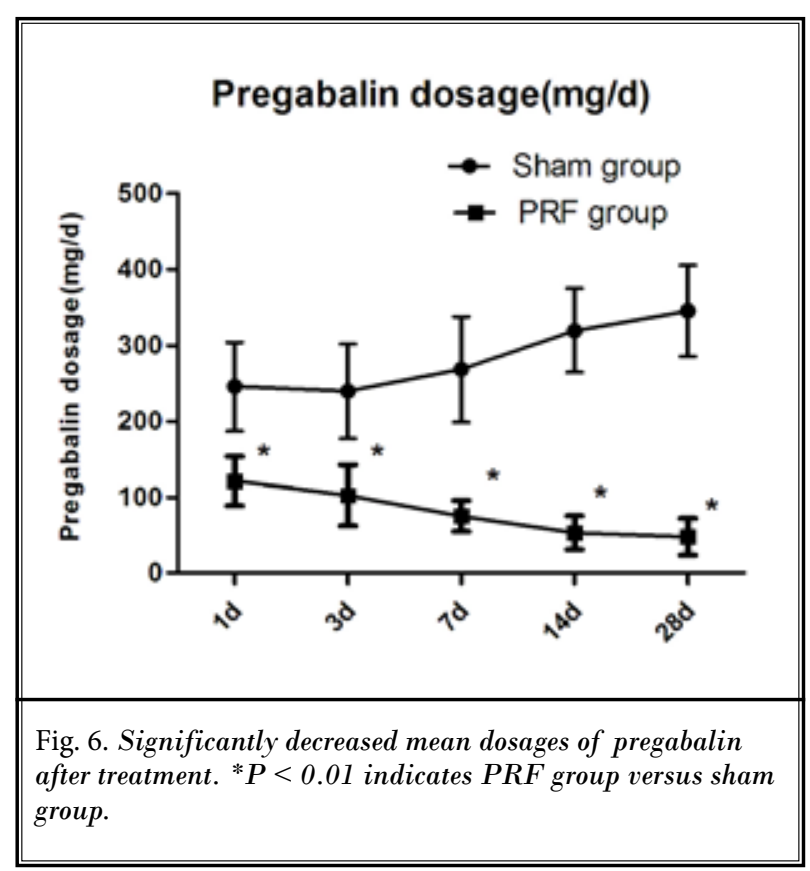

intensity was slowly increased to reduce the adverse reactions. Three patients in the PRF group and one patient in the sham group suffered bradycardia (heart rate $<60$ ) during puncturing through the foramen ovale; after they were administered atropine $(0.5 \mathrm{mg})$, the heart rate returned to 60 to 70 beats per minute. No patients withdrew during the treatment because of an adverse reaction.

After treatment, there was no bleeding at the puncture site, infection, intracranial hemorrhage, or 

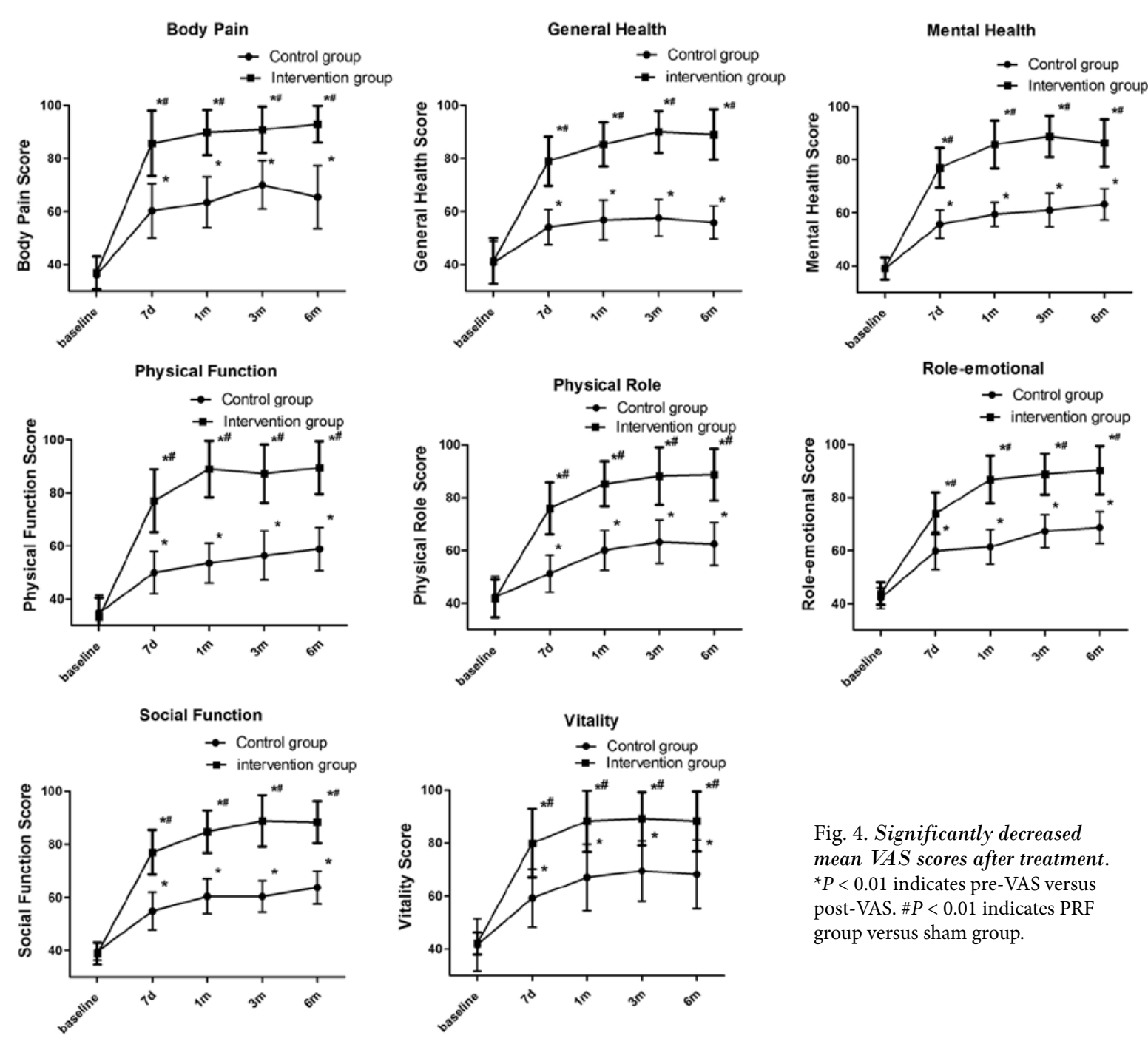

Fig. 4. Significantly decreased mean VAS scores after treatment. ${ }^{\star} P<0.01$ indicates pre-VAS versus post-VAS. $\# P<0.01$ indicates $P R F$ group versus sham group.

any other serious adverse effects. Seven patients in the PRF group and 14 patients in the sham group suffered ecchymoma on the face; however, they rapidly recovered without adverse effects during the follow-up period.

\section{Discussion}

$\mathrm{PHN}$ is a refractory chronic neuropathic pain that can develop following an acute $\mathrm{HZ}$ infection. It is neuropathic pain, which appears spontaneously, and is accompanied by allodynia and hyperalgesia in the damaged area (20). There is no definitive treatment algorithm devised for all patients with PHN (21-24). Therefore, it is important to find a method in treating acute/subacute episodes of HZ-associated pain and preventing their further development to $\mathrm{PHN}$.

Following $\mathrm{HZ}$ infection, the virus damages sensory neurons, which causes alterations in the composition, distribution, and functional characteristics of the transmembrane ion channels of sensory neurons. These damaged sensory neurons produce abnormal electric impulses, which are transmitted to the spinal cord and induce spontaneous pain $(25,26)$. Cell dehydration, decreased cell number, chronic inflammatory cell infiltration, and other pathological changes may occur in the dorsal root ganglion (27). The Gasserian ganglion is the affected target in trigeminal $\mathrm{HZ}$, thus, we treat the Gasserian ganglion as the therapeutic site. 
PRF is a technique that uses a discontinuous pulse current $(20 \mathrm{~ms}, 2 \mathrm{~Hz}$ ). Tissue temperature diffuses during intermittent time, and neuromodulation is used to relieve pain after nerve injury (28). Previous studies have reported some microdamage in axons (abnormal morphology of membrane and mitochondria, injury and disintegration of microfilaments and microtubules), and the higher extent of damage in $C$ fibers compared with A- $\delta$ fibers (29). PRF can selectively affect the axons of small diameter $C$ and A- $\delta$ nociceptive fibers, and can increase the expression of activating transcription activator 3 of $C$ and $A-\delta$ fibers (30). There is no significant correlation between its biological effects and thermal damage.

We have confirmed that bipolar high-voltage, long-duration PRF on diagnosis-related groups represents an effective and safe method for patients with PHN in our previous studies (16). Thus, in the current study, the voltage was gradually increased from $40 \mathrm{~V}$ to a maximum level according to the patient's individual level of tolerance (i.e., the level at which the patient was unable to tolerate the burning feeling, which represents thermal inductance from PRF). The absolute maximum was $100 \mathrm{~V}$. Previous research $(31,32)$ has demonstrated that increasing the exposure time to PRF current produced a significant anti-allodynic effect; thus, the longest PRF (900 seconds) for each patient was adopted in the current study.

In our study, we found that the patients in both groups obtained significantly decreased VAS scores after treatment $(P<0.01)$ and experienced significantly improved quality of life $(P<0.01)$. The comparison of indices in the 2 groups at each time point showed that the improvement in the PRF group was more significant, whereas that in the control group was less significant; the difference was statistically significant $(P$ $<0.01$ ), thus suggesting the effectiveness of PRF treatment. The dosage of pregabalin administered per day was significant lower in the PRF group than those in the sham group at each time point after treatment $(P<$ 0.01). Therefore, $P R F$ in the acute/subacute phase of $\mathrm{HZ}$ could be important for preventing the occurrence and development of PHN.

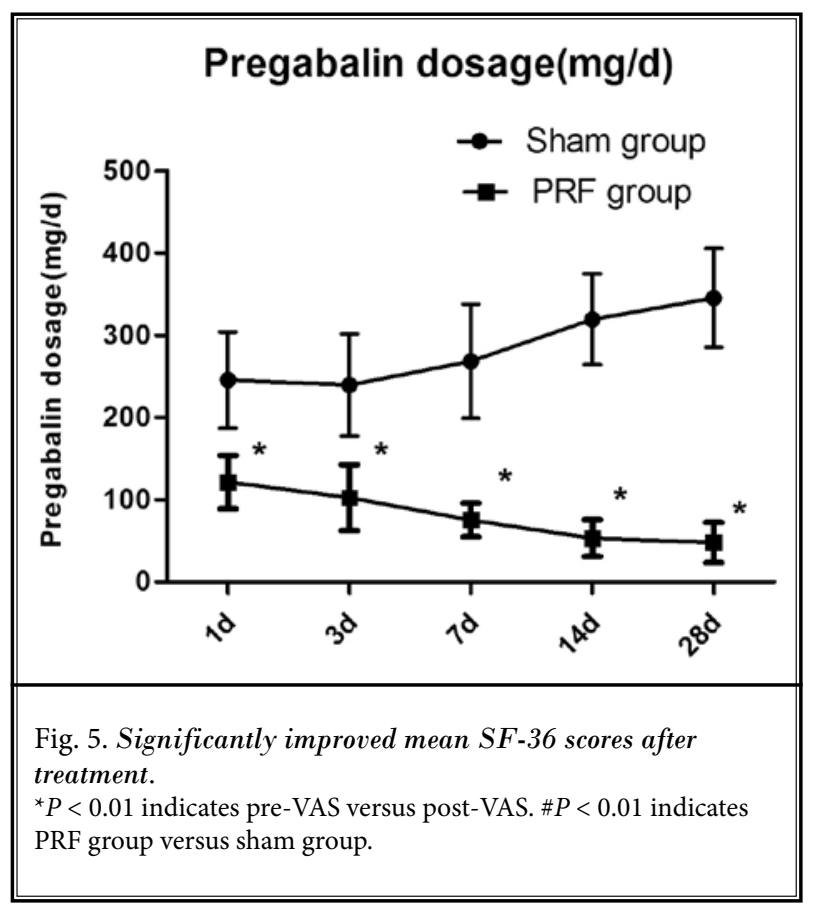

However, there were several limitations in our current study design, which should be addressed in future trials. First, the patients were recruited from a single center, and the sample size was relatively small. Second, the patients were only followed for 6 months after treatment. Future studies should include a large, prospective study across multiple sites and a longer length of follow-up. However, the current findings provide strong preliminary evidence that PRF is an effective pain relief method for acute/subacute zoster-related trigeminal neuralgia.

\section{Conclusions}

High-voltage, long-duration PRF on the Gasserian ganglion can obviously relieve the pain of acute/ subacute zoster-related trigeminal neuralgia, thus improving the quality of life and reducing the necessary dosage of antiepileptic drugs. 


\section{References}

$\{A \cup:$ Please check the references, in many cases, the second author only lists initials. Some have already been corrected\}

1. Sampathkumar P, Drage LA, Martin DP. Herpes zoster (shingles) and postherpetic neuralgia. Mayo Clin Proc 2009; 84:274-280.

2. Gershon AA, Gerhson MD, Breuer J, Levin MJ, Oaklander AL, Griffiths PD. Advances in the understanding of the pathogenesis and epidemiology of herpes zoster. J Clin Virol 2010; 48(Suppl 1):S2-7.

3. Curone M, Peccarisi C, Bussone G. Headache attributed to intracrania pressure alterations: Applicability of the International Classification of Headache Disorders ICHD-3 beta version versus ICHD-2. Neurol Sci 2015; 36(Suppl 1):137-139.

4. Bouhassira D, Chassany O, Gaillat J, Hanslik T, Launay O, Mann C, Rabaud C, Rogeaux O, Strady C. Patient perspective on herpes zoster and its complications: An observational prospective study in patients aged over 50 years in general practice. Pain 2012; 153:342-349.

5. Doth AH, Hansson PT, Jensen MP, Taylor RS. The burden of neuropathic pain: A systematic review and meta-analysis of health utilities. Pain 2010; 149:338-344.

6. Schlereth $T$, Heiland A, Breimhorst $M$, Fechir M, Kern U, Magerl W, Birklein F. Association between pain, central sensitization and anxiety in postherpetic neuralgia. Eur J Pain 2015; 19:193-201.

7. Johnson RW, Rice AS. Clinical practice. Postherpetic neuralgia. N Engl J Med 2014; 371:1526-1533.

8. Shannon HJ, Anderson J, Damle JS. Evidence for interventional procedures as an adjunct therapy in the treatment of shingles pain. Adv Skin Wound Care 2012; 25:276-284.

9. Forbes HJ, Thomas SL, Smeeth L, Clayton T, Farmer R, Bhaskaran K, Langan SM. A systematic review and meta-analysis of risk factors for postherpetic neuralgia. Pain 2016; 157:30-54.

10. Kawai K, Rampakakis E, Tsai TF, Cheong HJ, Dhitavat J, Covarrubias AO, Yang L, Cashat-Cruz M, Monsanto $\mathrm{H}$, Johnson K, Sampalis JS, Acosta CJ. Predictors of postherpetic neuralgia in patients with herpes zoster: A pooled analysis of prospective cohort studies from North and Latin America and Asia. Int J Infect Dis 2015; 34:126-131.

11. Gewandter JS, Dworkin RH, Turk DC, Farrar JT, Fillingim RB, Gilron I, Mark- man JD, Oaklander AL, Polydefkis MJ, Raja SN, Robinson JP, Woolf CJ, Ziegler $D$, Ashburn MA, Burke LB, Cowan P, George SZ, Goli V, Graff OX, lyengar $S$, Jay GW, Katz J, Kehlet $H$, Kitt RA, Kopecky EA, Malamut R, McDermott MP, Palmer P, Rappaport BA, Rauschkolb C, Steigerwald I, Tobias J, Walco GA. Research design considerations for chronic pain prevention clinical trials: IMMPACT recommendations. Pain 2015; 156:1184-1197.

12. Dong DS, Yu X, Wan CF, Liu Y, Zhao L, Xi Q, Cui WY, Wang QS, Song T. Efficacy of short-term spinal cord stimulation in acute/subacute zoster-related pain: A retrospective study. Pain Physician 2017; 20:E633-E645

13. Van Boxem K, Huntoon M, Van Zundert J, Patijn J, van Kleef $M$, Joosten EA. Pulsed radiofrequency: A review of the basic science as applied to the pathophysiology of radicular pain: A call for clinical translation. Reg Anesth Pain Med 2014; 39:149-159.

14. Cosman ER Jr, Cosman ER Sr. Electric and thermal field effects in tissue around radiofrequency electrodes. Pain Medicine (Malden, Mass) 2005; 6:405-424.

15. Ke M, Yinghui F, Yi J, Xeuhua H, Xiaoming L, Zhijun C, Chao H, Yingwei W. Efficacy of pulsed radiofrequency in the treatment of thoracic postherpetic neuralgia from the angulus costae: A randomized, double-blinded, controlled trial. Pain Physician 2014; 16:15-25.

16. Wan CF, Dong DS, Zhao L, Xi Q, Yu X, Cui WY, Wang QS, Song T. Bipolar highvoltage, long-duration pulsed radiofrequency improves pain relief in postherpetic neuralgia. Pain Physician 2016; 19:E721-E728.

17. Charlton E. Ethical guidelines for pain research in humans. Committee on Ethical Issues of the International Association for the Study of Pain. Pain 1995; 63:277-278.

18. Keller SD, Majkut TC, Kosinski M, Ware JE Jr. Monitoring health outcomes among patients with arthritis using the SF-36 Health Survey: Overview. Med Care 1999; 37(5 Suppl):MS1-9.

19. Stacey BR, Glanzman RL. Use of gabapentin for postherpetic neuralgia: Results of two randomized, placebocontrolled studies. Clin Ther 2003; 25:2597-2608.

20. Ding $\mathrm{Y}$, Li H, Hong T, Zhao R, Yao P, Zhao G. Efficacy and safety of computed tomography-guided pulsed radiofrequency modulation of thoracic dorsal root ganglion on herpes zoster neuralgia. Neuromodulation: Technology at the Neural Interface 2019; 22:108-114.\{AU: Please note updates to reference 20$\}$

21. Sacks GM. Unmet need in the treatment of postherpetic neuralgia. Am J Manag Care 2013; 19(1 Suppl):S207-213.

22. Finnerup NB, Attal N, Haroutounian S, McNicol E, Baron R, Dworkin RH, Gilron I, Haanpaa $M$, Hansson $P$, Jensen TS, Kamerman PR, Lund K, Moore A, Raja SN, Rice AS, Rowbotham M, Sena E, Siddall P, Smith BH, Wallace M. Pharmacotherapy for neuropathic pain in adults: A systematic review and metaanalysis. Lancet Neurol 2015; 14:162-173.

23. Kumar V, Krone K, Mathieu A. Neuraxial and sympathetic blocks in herpes zoster and postherpetic neuralgia: An appraisal of current evidence. Reg Anesth Pain Med 2004; 29:454-461.

24. Tyring SK. Management of herpes zoster and postherpetic neuralgia. J Am Acad Dermatol 2007; 57 (6 Suppl):S136-142.

25. Bartley J. Post herpetic neuralgia, schwann cell activation and vitamin D. Med Hypotheses 2009; 73:927-929.

26. Johnson RW. Herpes zoster in the immunocompetent patient: Management of post-herpetic neuralgia. Herpes 2003; 10:38-45.

27. Reichelt M, Zerboni L, Arvin AM. Mechanisms of varicella-zoster virus neuropathogenesis in human dorsal root ganglia. J Virol 2008; 82:3971-3983.

28. Perret DM, Kim DS, Li KW, Sinavsky K, Newcomb RL, Miller JM, Luo ZD. Application of pulsed radiofrequency currents to rat dorsal root ganglia modulates nerve injury-induced tactile allodynia. Anesth Analg 2011; 113:610-616.

29. Erdine S, Bilir A, Cosman ER, Cosman ER Jr. Ultrastructural changes in axons following exposure to pulsedradiofrequency fields. Pain Pract 2009; 9:407-417.

30. Hamann W, Abou-Sherif S, Thompson S, Hall S. Pulsed radiofrequency applied to dorsal root ganglia causes a selective increase in $\mathrm{ATF}_{3}$ in small neurons. Eur J Pain 2006; 10:171-176.

31. Tanaka N, Yamaga M, Tateyama S, Uno T, Tsuneyoshi I, Takasaki M. The effect of pulsed radiofrequency current on mechanical allodynia induced with resiniferatoxin in rats. Anesth Analg 2010; 111:784-790.

32. Abd-Elsayed A, Kreuger L, Seeger S, Dulli D. Pulsed radiofrequency for treating trigeminal neuralgia. Ochsner J 2018; 18:63-65. 